\title{
HPB SURGERY
}

\section{Operative mortality, blood loss and the use of Pringle manoeuvres in 526 consecutive liver resections}

\author{
JEFFREY T LORDAN, TIM R WORTHINGTON, NIAL QUINEY, WILLIAM J FAWCETT, \\ NARIMAN D KARANJIA
}

The Royal Surrey County Hospital, Guildford, Surrey, UK

ABSTRACT

INTRODUCTION Centres with high volumes of high-risk surgery have significantly better outcomes than low-volume centres for pancreatic resection, oesophagectomy and pelvic exenteration. However, this has not to date been conclusively demonstrated for hepatic resection. With increased experience, operative practice can change. The use of the Pringle manoeuvre reduced substantially over a 12-year period in a single centre as it was felt anecdotally that its use increased the incidence of hepatic insufficiency and operative mortality. This study was designed to review 12 years of experience in a single hepatobiliary centre. PATIENTS AND METHODS Data regarding 526 consecutive liver resections were prospectively recorded and retrospectively analysed in a high-volume referral unit over a 12-year period. Patients' demographics, operative mortality and morbidity were analysed on an annual basis.

RESULTS Overall peri-operative mortality was 1.9\%. Operative mortality in the first 6 years compared to the latter 6 years was $4.1 \%$ and $1.2 \%$, respectively $(P=0.13)$. The morbidity rate was $26.8 \%$ and $20.3 \%$ in the first and second halves of the study, respectively $(P=0.15)$. With increased experience, intra-operative blood loss and patients receiving blood transfusions decreased $(P=0.047$ and 0.03 , respectively) while the number of intra-operative Pringle manoeuvres also decreased $(P<0.0001)$. Hospital stay decreased significantly over the 12 years $(P=0.049)$.

CONCLUSIONS High-volume centres are the safest environment for hepatic resection. With increased experience, it may be possible to reduce the intra-operative use of the Pringle manoeuvre without increasing the intra-operative blood loss. This may be associated with a decrease in hepatic insufficiency and peri-operative mortality.

KEYWORDS

Hepatic resection - Operative mortality - Blood loss - Pringle manoeuvre

CORRESPONDENCE TO

Nariman Karanjia, Professor of Hepato-Pancreatico-Biliary Surgery, Royal Surrey County Hospital, Egerton Road, Guildford, Surrey GU2 7XX, UK. T: +44 (0)1483 464118; F: +44 (0)1483 402740;

E: nariman.karanjia@btinternet.com or nariman.karanjia@royalsurrey.nhs.uk

Major surgery is associated with substantial risk of morbidity and mortality. Studies have investigated factors that may influence or predict outcome. High-volumes centres have significantly better outcomes than low-volume centres for pancreatic resection $(5.8 \%$ and $12.9 \%$ in high-volume and low-volume centres, respectively), ${ }^{1,2}$ oesophagectomy $(3.4 \%$ and $17.3 \%$ in high-volume and low-volume centres, respectively), ${ }^{1,2}$ and pelvic exenteration. ${ }^{2}$ Other major surgical procedures including nephrectomy, pneumonectomy and cystectomy, however, have not yielded significant differences in outcome between high and low-volume units. ${ }^{1,2}$

Liver resections have a recognised morbidity (13-37\%) and operative mortality $(0-10 \%))^{3-5}$ However, the question regarding volume as a potential factor to influence outcome has not been conclusive answered within the literature.
Over the 12 years of the current study, it was felt by the senior surgeon (NDK) that the dogmatic approach of using a Pringle manoeuvre to reduce intra-operative bleeding resulted in a higher incidence of hepatic insufficiency and possibly peri-operative mortality. This study was designed to investigate the effects of increasing volume on patients' outcome following liver resection over a 12-year period and, specifically, to examine the effects of reducing the use of intra-operative Pringle manoeuvres.

\section{Patients and Methods}

Consecutive patients $(n=526)$ who underwent liver resections over 12 years (September 1996 to December 2007) were included. Data were recorded prospectively and analysed retrospectively. 
Pre-operative assessment was standardised using computerised tomography (CT) of the chest abdomen and pelvis (for those referred with primary or secondary malignant disorders) and magnetic resonance imaging (MRI) of the liver using intravenous Teslascan. Operative assessment included operative ultrasound scanning for malignant resections (Terason, CA, USA).

Patients were selected for hepatic resection according to the tumour size, number and anatomical distribution, presence of co-morbidity and the ability to preserve at least 30\% functioning liver parenchyma. For patients with malignant disorders, selection for hepatic resection also included the resectability of the primary tumour, presence of resectable extrahepatic metastases and achievable tumour-free margins within the liver taking into account anatomical distribution.

Patients referred with colorectal liver metastases were treated pre-operatively for 2-3 months with chemotherapy if they

\section{Table 1 Indications for hepatic resection}

$\begin{array}{ll}\text { Indications for hepatic resection } & \text { No. patients } \\ (n=526)\end{array}$

Colorectal metastases

Benign disease $(n=77)$

- Focal nodular hyperplasia 12

- Inflammatory changes 8

- Adenoma 3

- Cystic disease 33

- Haemangioma 14

- Trauma 23

- Scar tissue 3

Gynaecological metastases

- Uterine leiomyosarcoma 6

- Ovarian carcinoma 4

Breast metastases

- Invasive ductal carcinoma 3

- Invasive lobular carcinoma 2

- Ductal carcinoma in situ (CIS) 2

Cholangiocarcinoma 11

Gall bladder carcinoma 3

Carcinoid from small bowel $\quad 8$

Malignant melanoma 3

Gastric carcinoma $\quad 1$

Oesophageal carcinoma 2

Pulmonary carcinoma $\quad 1$

Pleural mesothelioma 1

Carcinoma of the ampulla 2

Carcinoma of the pancreas 2

Hepatocellular carcinoma $\quad 7$

Adenoid cystic carcinoma $\quad 1$ had synchronous or early metachronous metastases developing less than 2 years following diagnosis of their primary colorectal cancer. Patients with metachronous tumours diagnosed greater than 2 years after their primary colorectal tumour were only offered neo-adjuvant chemotherapy if they had tumours with potentially threatened resection margins. ${ }^{6,7}$

Objective data were recorded prospectively on a database (PMAS) with the help of a whole time data clerk. All pre-, periand postoperative factors were recorded including age, patients' demographics, diagnosis, intra-operative blood loss, blood chemistry, morbidity (intra- and postoperative), hospital stay, histology (including resection margins) and repeat procedures. Postoperative mortality was defined as death within hospital or within 30 days of surgery. All patients were followed up.

Statistical analyses including chi squared, $t$-tests, log ranking and Cox regression were performed using the Patient Management \& Analysis System 2004: Statistics Software, ${ }^{8,9}$ and SPSS v.15. $P$-values less than 0.05 was considered significant.

\section{Results}

The study included 526 consecutive liver resections. Table 1 shows the indications for hepatic resection. The majority ( $n=391)$ were carried out for colorectal liver metastases, 14 of which had repeat liver resections. Seventy-seven patients underwent liver resection for benign disease. Table 2 demonstrates the types of liver resections performed.

Table 3 shows patients' demographics and peri-operative outcomes, and compares the first half of the series (1996-2001) with the latter half (2002-2007). There was no difference in median age between the two halves of the series. The incidence of Pringle manoeuvre use reduced significantly from $91 \%$ in the first half to $40.2 \%$ during the latter half of the series $(P<0.0001)$. The median intra-operative blood loss also dropped significantly from $300 \mathrm{ml}$ to $250 \mathrm{ml}$, respectively $(P=0.047)$. There was a corresponding significant reduction in patients who received blood transfusions from $9.8 \%$ during first half of the series to $6.7 \%$ during the latter half of the series $(P=0.03)$. There was also a significant reduction in median hospital stay of 11 days during the first half to 9 days during the latter half of the study $(P=0.049)$.

\section{Table 2 Types of liver resection performed}

\begin{tabular}{lc} 
Type of resection & Number of p \\
\hline Segmentectomy & 174 \\
Right hepatectomy & 140 \\
Extended right hepatectomy & 86 \\
Left hepatectomy & 43 \\
Extended left hepatectomy & 45 \\
Wedge excision & 38
\end{tabular}


The overall complication rate dropped from $26.8 \%$ during the period 1996 to 2001 to $20.3 \%$ in the latter half of the study $(P=0.15)$ and there was a corresponding reduction in the incidence of hepatic insufficiency specifically $(3.3 \%$ to $1.5 \%$, respectively; $P=0.3$; Table 3 ). Peri-operative mortality also reduced from $4.1 \%$ during the first half of the series, to $1.2 \%$ during the latter half $(P=0.13)$.

Between 1996 and 2001, there were five peri-operative deaths. Three died due to hepatic insufficiency, one due to left ventricular failure and one due to pneumonia followed by a massive upper gastrointestinal bleed. Between 2002 and 2007 , there were also five peri-operative deaths. One was due to a cerebral abscess, one due to hepatic insufficiency, two due to sepsis and multi-organ dysfunction and one secondary to a thrombo-embolic event which required anticoagulation but who subsequently developed bleeding and renal failure.

Tables 4 and 5 and Figure 1 demonstrate the analyses of outcomes and indications for liver surgery for each year of the study. The number of patients who underwent liver

Table 3 Patients' demographics and outcomes in the first half of the series versus the second half of the series $(n=526)$

\begin{tabular}{|c|c|c|c|}
\hline & $1996-2001(n=123)$ & $2002-2007(n=403)$ & $P$-value \\
\hline Median age in years (range) & $64(20.6-82.6)$ & $63.8(20.9-85.4)$ & 0.49 \\
\hline Male:female ratio & $1: 1$ & $1.1: 1$ & \\
\hline \multicolumn{4}{|l|}{ ASA } \\
\hline 1 & 29 & 94 & \\
\hline 2 & 52 & 215 & \\
\hline 3 & 12 & 54 & \\
\hline 4 & 0 & 7 & \\
\hline Not recorded & 30 & 33 & \\
\hline Median intra-operative blood loss in $\mathrm{ml}$ (range) & $300(0-4000)$ & $250(0-8000)$ & 0.047 \\
\hline Patients who received blood transfusions (\%) & $12(9.8 \%)$ & $27(6.7 \%)$ & 0.03 \\
\hline Hospital stay in days (range) & $11(5-47)$ & $9(1-67)$ & 0.049 \\
\hline Number of Pringle manoeuvres & $112(91 \%)$ & $162(40.2 \%)$ & $<0.0001$ \\
\hline Complications (\%) & $33(26.8 \%)$ & $82(20.3 \%)$ & 0.15 \\
\hline Hepatic insufficiency (\%) & $4(3.3)$ & $6(1.5)$ & 0.3 \\
\hline Peri-operative mortality (\%) & $5(4.1 \%)$ & $5(1.2 \%)$ & 0.13 \\
\hline
\end{tabular}

\section{Table 4 Outcomes during each year of the study}

\begin{tabular}{|c|c|c|c|c|c|c|c|c|c|c|c|c|}
\hline Year of study & 1996 & 1997 & 1998 & 1999 & 2000 & 2001 & 2002 & 2003 & 2004 & 2005 & 2006 & 2007 \\
\hline No. of liver resections & 1 & 8 & 16 & 29 & 34 & 35 & 45 & 56 & 65 & 79 & 73 & 85 \\
\hline $\begin{array}{l}\text { No. of complications } \\
\text { (\%) }\end{array}$ & 0 & $\begin{array}{c}3 \\
(37.5)\end{array}$ & 0 & $\begin{array}{c}4 \\
(13.8)\end{array}$ & $\begin{array}{c}14 \\
(41.2)\end{array}$ & $\begin{array}{c}12 \\
(34.3)\end{array}$ & $\begin{array}{c}9 \\
(20)\end{array}$ & $\begin{array}{c}17 \\
(30.4)\end{array}$ & $\begin{array}{c}10 \\
(15.4)\end{array}$ & $\begin{array}{c}21 \\
(26.6)\end{array}$ & $\begin{array}{c}10 \\
(13.7)\end{array}$ & $\begin{array}{c}15 \\
(17.6)\end{array}$ \\
\hline $\begin{array}{l}\text { Number of } 2 \text { post- } \\
\text { operative deaths (\%) }\end{array}$ & 0 & $\begin{array}{c}1 \\
(12.5)\end{array}$ & 0 & $\begin{array}{c}1 \\
(3.4)\end{array}$ & $\begin{array}{c}2 \\
(5.9)\end{array}$ & $\begin{array}{c}1 \\
(2.9)\end{array}$ & 0 & 0 & $\begin{array}{c}1 \\
(1.5)\end{array}$ & $\begin{array}{l}0 \\
0\end{array}$ & $\begin{array}{c}2 \\
(2.7)\end{array}$ & $\begin{array}{c}3 \\
(3.5)\end{array}$ \\
\hline $\begin{array}{l}\text { Number of Pringle } \\
\text { manoeuvres (\%) }\end{array}$ & $\begin{array}{c}1 \\
(100)\end{array}$ & $\begin{array}{c}8 \\
(100)\end{array}$ & $\begin{array}{c}14 \\
(87.5)\end{array}$ & $\begin{array}{c}29 \\
(100)\end{array}$ & $\begin{array}{l}32 \\
(94)\end{array}$ & $\begin{array}{c}28 \\
(80)\end{array}$ & $\begin{array}{c}37 \\
(82)\end{array}$ & $\begin{array}{c}44 \\
(78)\end{array}$ & $\begin{array}{l}29 \\
(45)\end{array}$ & $\begin{array}{c}28 \\
(35)\end{array}$ & $\begin{array}{c}11 \\
(15)\end{array}$ & $\begin{array}{l}13 \\
(15)\end{array}$ \\
\hline $\begin{array}{l}\text { Median blood } \\
\text { loss in ml (range) }\end{array}$ & 50 & $\begin{array}{c}1450 \\
(1070- \\
2500)\end{array}$ & $\begin{array}{c}675 \\
(35- \\
4000)\end{array}$ & $\begin{array}{c}300 \\
(50- \\
2000)\end{array}$ & $\begin{array}{l}350 \\
(<20- \\
1000)\end{array}$ & $\begin{array}{c}200 \\
(10- \\
1200)\end{array}$ & $\begin{array}{l}200 \\
(<20- \\
2000)\end{array}$ & $\begin{array}{l}200 \\
(<20- \\
2000)\end{array}$ & $\begin{array}{c}200 \\
(<20- \\
800)\end{array}$ & $\begin{array}{l}250 \\
(<20- \\
8000)\end{array}$ & $\begin{array}{l}350 \\
(<20- \\
6000)\end{array}$ & $\begin{array}{l}300 \\
(<20- \\
3000)\end{array}$ \\
\hline $\begin{array}{l}\text { Median hospital } \\
\text { stay in days (range) }\end{array}$ & 25 & $\begin{array}{c}15 \\
(11-38)\end{array}$ & $\begin{array}{c}11 \\
(8-18)\end{array}$ & $\begin{array}{l}11.5 \\
(6-32)\end{array}$ & $\begin{array}{c}10 \\
(6-47)\end{array}$ & $\begin{array}{c}9 \\
(5-28)\end{array}$ & $\begin{array}{c}11 \\
(6-34)\end{array}$ & $\begin{array}{c}11 \\
(6-48)\end{array}$ & $\begin{array}{c}11 \\
(7-53)\end{array}$ & $\begin{array}{c}9 \\
(5-38)\end{array}$ & $\begin{array}{c}8 \\
(1-67)\end{array}$ & $\begin{array}{c}8 \\
(1-55)\end{array}$ \\
\hline
\end{tabular}




\section{Table 5 Indications for liver resection for each year studied}

\begin{tabular}{|c|c|c|c|c|c|c|c|c|c|c|c|c|}
\hline Year of study & 1996 & 1997 & 1998 & 1999 & 2000 & 2001 & 2002 & 2003 & 2004 & 2005 & 2006 & 2007 \\
\hline Colorectal cancer & & 6 & 7 & 21 & 25 & 28 & 33 & 44 & 51 & 57 & 49 & 70 \\
\hline Breast carcinoma & 1 & 1 & 1 & 2 & & 1 & & & & & & 1 \\
\hline Benign disease & & & 5 & 6 & 5 & 3 & 6 & 6 & 8 & 17 & 17 & 4 \\
\hline Cholangiocarcinoma & & & & & & & 2 & 2 & & 1 & 3 & 3 \\
\hline Hepatocellular carcinoma & & & & & 1 & & 1 & & 1 & 2 & & 2 \\
\hline Gynaecological malignancy & & & 2 & & & 1 & 1 & 1 & & 1 & 2 & 2 \\
\hline Carcinoid & & & & & 2 & 2 & & & 2 & 1 & 1 & \\
\hline Malignant melanoma & & & 1 & & & & 1 & & & & & 1 \\
\hline Gastric/oesophageal carcinoma & & & & & & & 1 & 1 & & & 1 & \\
\hline Pulmonary/mesothelioma & & & & & & & & 2 & & & & \\
\hline Gall bladder carcinoma & & 1 & & & & & & & & & & 2 \\
\hline Pancreatic/ampullary cancer & & & & & 1 & & & & 2 & 1 & & \\
\hline
\end{tabular}

resection during each year increased with experience. After year 5 , there was a substantial trend towards a reduction in the use of intra-operative Pringle manoeuvres. This corresponded with a trend towards reduced intra-operative blood loss and subsequent blood transfusions required. There was also a trend towards reduced overall complication rate, peri-operative mortality and hospital stay.

\section{Discussion}

The literature has provided several definitions of the minimum case load required to name a centre high-volume, ranging from $>1$ to $>22$ cases per year. ${ }^{1,10-12}$ Some studies have demonstrated a significant improvement in the operative mortality for liver resections within high-volume versus low-volume centres

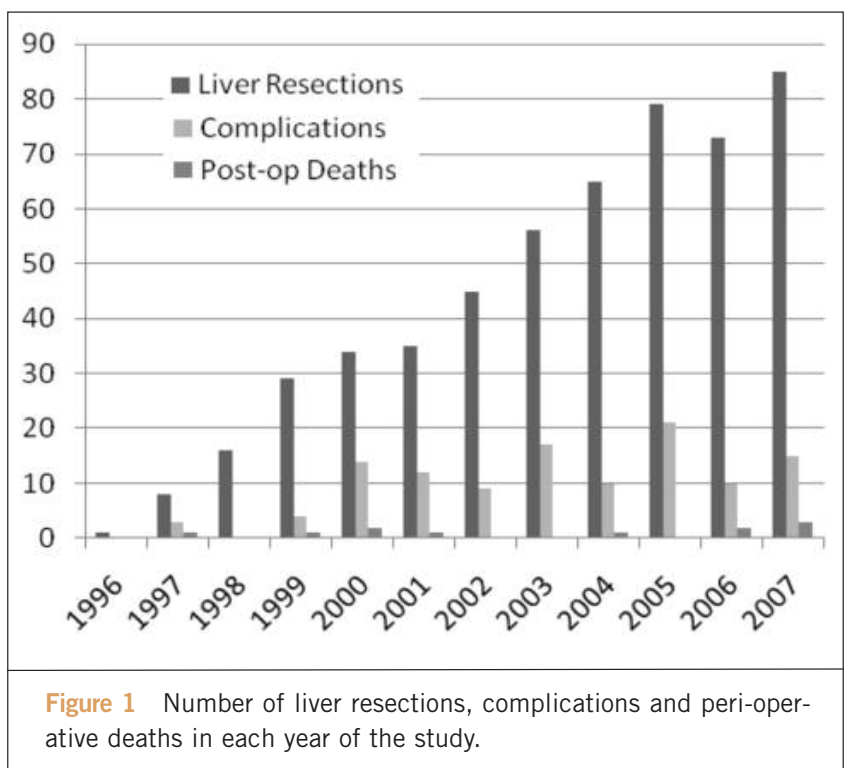

(22.7\% vs $9.4 \%$ and $10.2 \%$ vs $2.8 \%),{ }^{13-15}$ while others have reported comparable results between high- and low-volume centres, ${ }^{12,16}$ suggesting that no consensus has yet been reached in the literature.

The aim of this article was to study the outcomes of all liver resections as volume and experience increased. It was felt anecdotally by the senior surgeon (NDK) that use of the intra-operative Pringle manoeuvre may be associated with an increased incidence of hepatic insufficiency, complications in general, and possibly peri-operative mortality, due to the subsequent warm ischaemic injury endured by the liver. Practice changed during the 12 years, with a significant reduction in the use of intra-operative Pringle manoeuvres. However, there was a corresponding reduction in intra-operative bleeding and blood transfusion rate. It is likely that, with increased experience, operative techniques improve allowing the reduced employment of the Pringle manoeuvre. Improvements in equipment such as haemostatic devices, staplers, dissection equipment such as the CUSA (Cavitron Ultrasonic Surgical Aspirator), and reducing the intraoperative central venous pressure have likely contributed to allow reduced use of Pringle manoeuvres while reducing the median intra-operative blood loss. ${ }^{17-19}$

However, the centre in which these data were acquired did not reach a through-put that would be considered as 'high volume' until the latter years of the study. It is possible, therefore, that this may have skewed the results. Another factor which may have biased the results in this study lies in the small numbers of hepatic resections for non-colorectal liver metastases including HCC, cholangiocarcinoma, stomach, oesophagus and ampullary/pancreatic neoplasms. The variety of therapy modalities that may be employed in treating these different tumours undoubtedly affects outcome. It is difficult, therefore, to analyse conclusively the effects of intra-operative Pringle manoeuvres in these small volume groups. 
While this study shows that the use of intra-operative Pringle manoeuvres can be safely reduced, one must question whether outcome is affected by reducing the intra-operative use of the Pringle manoeuvre. These data show that the complication rate reduced over the years and, specifically, the incidence of hepatic insufficiency, as did the peri-operative mortality rate. Also, it was notable that the mortality directly related to hepatic insufficiency also dropped substantially from $2.4 \%$ in the early half of the series to $0.25 \%$. However, none of these achieved significance. This may be explained by the small number of patients affected and the fact that the incidence of Pringle manoeuvres did not reduce to the level normally seen in 'high-volume centres' until the latter years of the study.

Complications following high-risk surgery have been shown to correlate with mortality in large population based studies. ${ }^{12,20,21}$ Dimick et al ${ }^{13}$ showed that the peri-operative morbidity in low-volume centres was $64.8 \%(n=147)$ and high-volume hospitals was $36 \%(n=422)$. During the latter half of the current study, complication rates dropped to $20.3 \%$, which is substantially lower than other reported series.

With each year of our study, there was a substantial increase in the number of liver resections being performed; with that increase in experience, more liver resections were carried out for benign disease. With low morbidity and mortality rates, it would be appropriate to consider patients with benign liver conditions for hepatic resection. However, this would be difficult to justify in low-volume centres with less experience and higher morbidity and mortality rates.

Early patient outcome following surgery is multifactorial. This conclusion is supported by studies which have shown lowvolume surgeons in high-volume centres achieving similar results to high-volume surgeons. ${ }^{16,22}$ If volume is an influential factor to patients' outcome, the debate continues whether it is the hospital or the surgeon that require the volume of experience. Alongside surgical experience, high-volume centres have increased anaesthetic, nursing, intensive care and physiotherapy experience. $^{12,13}$

\section{Conclusions}

The data suggest that high-volume centres are the safest environment for hepatic resection. With increased experience, it is possible to reduce the intra-operative use of Pringle manoeuvres, while continuing to reduce the intraoperative blood loss and transfusion rates. This change in practice may be associated with a reduction in morbidity, hepatic insufficiency specifically, hospital stay, overall perioperative mortality and peri-operative morbidity directly related to hepatic insufficiency.

\section{References}

1. Finlayson EV, Goodney PP, Birkmeyer JD. Hospital volume and operative mortality in cancer surgery. Arch Surg 2003; 138: 721-6.
2. Begg CB, Cramer LD, Hoskins WJ, Brennan MF. Impact of hospital volume on operative mortality for major cancer surgery. JAMA 1998; 280: 1747-51.

3. Lise M, Da Pian PP, Nitti D, Pilati PL, Prevaldi C. Colorectal metastases to the liver: present status of management. Dis Colon Rectum 1990; 33: 688-94.

4. McKay A, Dixon E, Taylor M. Current role of radiofrequency ablation for the treatment of colorectal liver metastases. Br J Surg 2006; 93: 1192-201.

5. Yasui K, Shimizu Y. Surgical treatment for metastatic malignancies. Anatomical resec tion of liver metastases: indications and outcome. Int J Clin Oncol 2005; 10: 86-96.

6. Karanjia ND, Lordan JT, Fawcett WJ, Quiney N, Worthington TR. Survival and recurrence after neo-adjuvant chemotherapy and liver resection for colorectal metastases - a ten year study. Eur J Surg Oncol 2009; In press.

7. Lordan JT, Karanjia ND, Quiney N, Fawcett WJ, Worthington TR. A 10 year study of outcome following hepatic resection for colorectal liver metastases the effect of evaluation in a multi-disciplinary team setting. Eur J Surg Oncol 2009; 35: 302-6.

8. Peto R, Pike MC, Armitage P, Breslow NE, Cox DR, Howard SV et al. Design and analysis of randomized clinical trials requiring prolonged observation of each patient. I. Introduction and design. Br J Cancer 1976; 34: 585-612.

9. Peto R, Pike MC, Armitage P, Breslow NE, Cox DR, Howard SV et al. Design and analysis of randomized clinical trials requiring prolonged observation of each patient. II. Analysis and examples. Br J Cancer 1977; 35: 1-39.

10. Jarnagin WR, Gohen M, Fong Y. Improvement in perioperative outcome after hepatic resection: analysis of 1800 consecutive cases over the past decade. Ann Surg 2002; 236: 397-407.

11. Petrelli NJ., Gupta B, Piedmonte M, Herrera L. Morbidity and survival of liver resection for colorectal adenocarcinoma. Dis Colon Rectum 1991; 34: 899-904.

12. Stone ME, Rehman SU, Conaway G, Sardi A. Hepatic resection at a community hospital. J Gastrointest Surg 2000; 4: 349-53.

13. Dimick JB, Pronovost PJ, Cowan Jr JA, Lipsett PA. Postoperative complication rates after hepatic resection in Maryland hospitals. Arch Surg 2003; 138: 41-6.

14. Glasgow RE, Showstack JA, Katz PP, Corvera CU, Warren RS, Mulvihill SJ. The relationship between hospital volume and outcomes of hepatic resection for hepatocellular carcinoma. Arch Surg 1999; 134: 30-5.

15. Choti MA, Bowman HM, Pitt HA. Should hepatic resection be performed at high-volume referral centres? J Gastrointest Surg 1998; 2: 11-20.

16. Metreveli RE, Sahm K, Denstman F, Abdel-Misih R, Petrelli NJ. Hepatic resection at a major community-based teaching hospital can result in good outcome. Ann Surg Oncol 2005; 12: 133-7.

17. Fong Y, Fortner J, Sun RL. Clinical scores for predicting recurrence after hepatic resection for metastatic colorectal cancer; analysis of 1001 consecutive cases. Ann Surg 1999; 230: 309-18.

18. Malafosse R, Penna C, Sa CA. Surgical management of hepatic metastases from colorectal malignancies. Ann Oncol 2001; 12: 887-94.

19. Scheele J., Altendorf-Hofmann A, Grube T. Resection of colorectal liver metastases. What prognostic factors determine patient selection? Chirurg 2001; 72: 547-60.

20. Dimick JB, Pronovost PJ, Lipsett PA. Complications and cost after high risk surgery: where should we focus our quality improvement efforts? Crit Care Med 2001; 29 (Suppl): A161.

21. Kalish RL, Daley J, Duncan CC. Costs of potential complications of care for major surgery patients. Am J Med Qual 1995; 10: 48-54.

22. Harmon JW, Tang DG, Gordon TA. Hospital volume can serve as a surrogate for surgeon volume for achieving excellent outcomes in colorectal resection. Ann Surg 1999; 230: 404-13. 